\title{
UTILIZAÇÃO DO ENADE (EXAME NACIONAL DE DESEMPENHO DE ESTUDANTES) COMO FERRAMENTA DE AVALIAÇÃO DO DESEMPENHO DE ALUNOS DE UMA INSTITUIÇÃO DE ENSINO SUPERIOR PAULISTANA
}

USE OF ENADE (EXAME NACIONAL DE DESEMPENHO DE ESTUDANTES) AS A TOOL FROM EVALUATION OF A HIGHER EDUCATION INSTITUTION STUDENTS LOCATED IN SÃO PAULO - BRAZIL

\section{Marcus Vinicius Cesso}

Mestre em Administração pela Universidade Nove de Julho (Uninove). E-mail: marcus.cesso@gmail.com (Brasil).

\section{Renato Ribeiro Nogueira Ferraz}

Professor Colaborador do Programa de Pós-Graduação em Administração (PPGA) e Professor Permanente do Programa de Mestrado Profissional em Administração - Gestão em Sistemas de Saúde (PMPA-GSS) - ambos da Uninove. E-mail: renatobio@ hotmail.com (Brasil).

Data de recebimento do artigo: 20-12-2016

Data de aceite do artigo: 05-12-2017 Doi: http://dx.doi.org/10.7769/gesec.v8i3.627 


\title{
UTILIZAÇÃO DO ENADE (EXAME NACIONAL DE DESEMPENHO DE ESTUDANTES) COMO FERRAMENTA DE AVALIAÇÃO DO DESEMPENHO DE ALUNOS DE UMA INSTITUIÇÃO DE ENSINO SUPERIOR PAULISTANA
}

\section{RESUMO}

Este artigo tem como objetivo justificar a aplicação do Exame Nacional de Desempenho de Estudantes - Enade - como ferramenta para avaliação do desempenho discente no curso de graduação em Administração de uma Instituição de Ensino Superior - IES, contribuindo para a gestão e melhoria dos resultados de ensino. Utilizou-se uma abordagem qualitativa de pesquisa documental em que foram analisados os últimos relatórios disponibilizados pelo Instituto Nacional de Estudos e Pesquisas Educacionais Anísio Teixeira - Inep - como forma de evolução do desempenho discente, seguindo os critérios do Enade em uma IES da cidade de Guarulhos. Por meio do acesso público aos Relatórios do Enade, a IES pôde promover suas intervenções em cinco critérios estabelecidos, que permitissem verificar a adesão do corpo discente no dia do exame, a média das notas obtidas no Enade, a percepção da prova, o perfil socioeconômico dos alunos e o processo de ensino-aprendizagem.

Palavras-chave: Enade. Avaliação do Ensino Superior. Desempenho discente. Estratégia.

\section{USE OF ENADE (EXAME NACIONAL DE DESEMPENHO DE ESTUDANTES) AS A TOOL FROM EVALUATION OF A HIGHER EDUCATION INSTITUTION STUDENTS LOCATED IN SÃO PAULO - BRAZIL}

\begin{abstract}
This paper aims to justify the application of the National Exam of Students Performance (Enade, in Portuguese) as a tool for assessing the students' performance in Management undergraduate course from a Higher Education Institution - HEI, contributing to evaluation and improvement of educational quality. A qualitative method by documentary research was used to analyze the last reports provided by the Instituto Nacional de Estudos e Pesquisas Educacionais Anísio Teixeira (Inep) as a form of measuring the student's performance, based on Enade's criteria, in an HEI located in Guarulhos. By means of the public access to Enade records, the HEI could promote its interventions in five established criteria that allowed verifying the presence of the students on the exam day, the average of the grades obtained in Enade, the examination perceptions, the students' socioeconomic profile, and the teachinglearning process.
\end{abstract}

Keywords: Enade. Evaluation of Higher Education. Student's Performance. Strategy. 


\section{INTRODUÇÃO}

Desde a década de 1950, a avaliação do ensino superior brasileiro vem sendo discutida por meio de diversas ações que se iniciaram com a Coordenação de Aperfeiçoamento de Pessoal de Nível Superior - Capes - focadas nos programas de nível strictu sensu como forma de aprimoramento da qualidade do ensino oferecido pelas Instituições de Ensino Superior - IES. Porém, foi a partir da década de 1980 que os programas de graduação foram inseridos no processo de avaliação da qualidade do Ensino Superior por meio de diversas iniciativas, como o Programa de Avaliação da Reforma Universitária - Paru, Comissão para a Reformulação da Educação Superior - "Comissão de Notáveis" e o Grupo Executivo para a Reforma da Educação Superior - Geres, sendo todos oriundos de órgãos governamentais (Polidori, Marinho-Araujo, \& Barreyro, 2006).

Diante dessas diversas iniciativas propostas pelos órgãos governamentais, as IES desenvolveram seus processos de autoavaliação, que no início eram individuais e que não permitiam uma padronização de critérios de avaliação entre as Instituições. Assim, visando esta padronização e a importância vista pelas IES de uma avaliação institucional profunda, foi criado o Sistema Nacional de Avaliação da Educação Superior - Sinaes, que tem como objetivo padronizar os parâmetros para uma avaliação uniforme feita pelos órgãos governamentais responsáveis pela mensuração da qualidade do ensino superior brasileiro, assim como pelo desempenho das IES, tanto no âmbito institucional, como do corpo docente e, principalmente, do corpo discente (Polidori et al., 2006).

A avaliação do desempenho dos discentes é o grande diferencial na mensuração feita pelo Sinaes (Polidori et al., 2006), pois é a partir deste eixo que as IES, por meio de seus gestores, podem promover mudanças significativas nas questões acadêmicas e, consequentemente, gerar mudanças nos eixos de avaliação institucional e dos cursos de graduação (Barreyro, 2008). Dessa forma, o Sinaes criou o Exame Nacional de Desempenho de Estudantes - Enade - a fim de contribuir para a melhoria da qualidade do ensino superior brasileiro, a partir do desempenho do discente (Inep, 2016).

O Enade é um exame que abrange um elevado número de alunos (Brito, 2008) e, conforme Polidori et al. (2006), este exame avalia o desempenho de competências dos discentes, além da relação ensino-aprendizado na qual está inserido. Com os resultados obtidos no Enade, as IES podem promover melhorias na qualidade do ensino, mudar metodologias e práticas educacionais em seus cursos de graduação e comparar o desempenho dos discentes em relação à amostra nacional, da sua região/cidade e de alunos dos mesmos 
cursos avaliados em outras IES (Barreyro, 2008; Inep, 2016; Polidori et al., 2006). Porém, as IES ainda não utilizam as informações oriundas do Relatório dos Resultados do Enade para promover ações estratégicas que auxiliem na melhora da qualidade de seus serviços de ensino, atraindo novos alunos para seus cursos de graduação (Brito, 2008).

Diante do que foi exposto até o momento, este estudo tem como pergunta de pesquisa: Como a aplicação do Enade pode ser uma ferramenta para avaliação do desempenho discente em um curso de graduação de uma IES?

Para responder à referida questão, neste artigo é utilizado o método de pesquisa documental por meio da análise dos Relatórios de Resultados do Enade, referentes ao curso de Administração de uma IES localizado na cidade de Guarulhos, São Paulo, e publicado no site do Inep. Os relatórios apresentam cinco critérios para avaliação do desempenho discente por parte das IES e que permitem verificar: 1) a adesão do corpo discente no dia do exame; 2) a média das notas obtidas no Enade; 3) a percepção da prova pelo discente; 4) o perfil socioeconômico dos alunos; 5) o processo de ensino-aprendizagem. Com a análise desses critérios, o curso de graduação obtém seu Conceito Enade, auxiliando a IES na gestão de seus resultados de seus serviços de ensino para toda a comunidade.

Nesse contexto, o objetivo deste artigo é justificar a aplicação do Exame Nacional de Desempenho de Estudantes - Enade como ferramenta para avaliação do desempenho discente no curso de graduação em Administração de uma IES, contribuindo para a gestão e melhoria dos resultados de seus serviços de ensino.

Além desta Introdução, segue-se a seção de "Referencial Teórico", que apresenta as teorias necessárias para compreensão do estudo. Na sequência, na seção de "Metodologia", são apresentadas as fontes das pesquisas documentais e é detalhada a IES objeto deste artigo, além do foco na escolha pelo curso de Administração para análise. A seguir, na seção "Apresentação e Discussão dos Resultados", relatam-se os indicadores e intervenções feitas pela IES que impactaram para a nota do curso de Administração da IES. Finalmente, na seção "Conclusões", argumenta-se sobre a realização dos objetivos propostos inicialmente, além das limitações do trabalho e sugestões de pesquisas futuras.

\section{REVISÃO DA LITERATURA}

O ensino superior brasileiro tem recebido cada vez mais atenção dos órgãos governamentais com foco na avaliação da qualidade dos serviços prestados pelas IES junto 
aos seus públicos internos e externos (Polidori et al., 2006). Por isso, o papel do gestor dessas instituições vem sendo cada vez mais importante para definição de planos e estratégias que possam atender as recomendações dos órgãos governamentais, possibilitando uma prestação de contas de forma objetiva e clara. Além disso, em um cenário cada vez mais competitivo, o papel deste gestor é ainda mais relevante para encontrar formas de atender a todos os públicos, melhorando seu desempenho organizacional e mantendo sua sustentabilidade financeira (Galvão, Corrêa, \& Alves, 2011).

Assim, os públicos envolvidos no processo do ensino superior brasileiro como órgãos governamentais, funcionários das IES, docentes e discentes destas instituições, pressionam as organizações a encontrar ferramentas que permitam um desempenho organizacional mais pleno (Galvão et al., 2011) e resultados mensuráveis para uma avaliação da qualidade dos serviços prestados (Brito, 2008; Polidori et al., 2006; Schwartzman, 2008).

As IES têm utilizado diversas ferramentas para mensurar seu desempenho institucional, docente e discente, sendo que, conforme Polidori et al. (2006), a avaliação do desempenho dos discentes é o grande diferencial na mensuração feita pelas IES, que se utilizam do Enade como ferramenta estratégica para esta avaliação de desempenho.

\subsection{Avaliações do desempenho organizacional}

A tomada de decisão nas organizações é cada vez mais importante para que os objetivos propostos no planejamento estratégico sejam alcançados e aumente-se o desempenho organizacional frente a outros concorrentes no mercado (Galvão et al., 2011). Além disso, qualquer tomada de decisão requer conhecimento prévio de todos os envolvidos neste processo para que aconteça de forma rápida e eficaz, possibilitando uma mensuração prática do desempenho organizacional (Borges, Cabral, \& Petri, 2014).

Conforme Lotta (2002), o desempenho nas organizações é uma comparação entre a expectativa e os resultados finais obtidos por todos os indivíduos inseridos no processo organizacional. Já para Galvão et al. (2011), o desempenho organizacional é uma medida necessária para a tomada das melhores decisões, por parte dos gestores, frente a um ambiente competitivo em que todas as organizações estão inseridas. Ambas as definições sobre desempenho organizacional são compartilhadas por Côrrea e Hourneaux Jr. (2008) que destacam que se não houver uma mensuração profunda dos resultados dos indivíduos na organização, aliada a uma gestão estratégica feita pelos administradores, a avaliação do 
desempenho do público interno será muito difícil, resultando em ações que não atenderão as expectativas internas e externas.

Assim, a avaliação do desempenho organizacional é muito importante para que as empresas se sustentem em um ambiente cada vez mais agressivo, em termos de concorrência empresarial (Corrêa \& Hourneaux Jr., 2008; Galvão et al., 2011; Lotta, 2002). Porém, conforme Martins e Neto (1998), para uma avaliação de desempenho completa, é necessário assumir indicadores que possibilitem uma análise dos resultados obtidos pela organização, por meio de dados prévios e posteriores à aplicação de tais indicadores. Com este comparativo, os gestores organizacionais conseguem obter parâmetros para medir o desempenho de suas organizações e da concorrência, tomando decisões mais assertivas, de forma a combater a alta concorrência presente em todos os mercados atualmente.

Tal nível de concorrência é notado no mercado educacional com o aumento significativo de IES no Brasil. Conforme Gomes et al. (2015), é essencial que os gestores educacionais avaliem indicadores de desempenho organizacional para que possam estabelecer as ações estratégicas das IES, devido à alta concorrência presente nos últimos anos em decorrência do aumento da oferta de cursos na área de ensino superior no Brasil. Este movimento dos últimos anos no mercado educacional obriga os gestores de IES a encontrarem formas de avaliação de desempenho que consigam atender aos órgãos responsáveis pela mensuração da qualidade do ensino no Brasil, além de atender as expectativas do seu público interno e externo. Assim, Kennerley e Neely (2003) ressaltam que todas as organizações, independente de seu segmento, devem acompanhar todas as mudanças para que tenham ferramentas para mensuração do desempenho organizacional.

Sendo assim, as IES têm buscado, constantemente, ferramentas de avaliação do seu desempenho institucional que consigam permitir que melhorem seus resultados e atendam aos níveis de qualidade na prestação de serviços educacionais recomendados pelo MEC (2004).

\subsection{Ferramentas de avaliação de desempenho usadas pelas IES}

A avaliação do ensino superior brasileiro intensificou-se na década de 1970, por meio de iniciativas propostas pela Capes, dedicadas em um primeiro momento ao âmbito de mensuração da qualidade de cursos de nível de stricto sensu. Entretanto, somente em meados da década de 1980 as avaliações de cursos de ensino superior englobaram os cursos de graduação, especialmente em decorrência de diversas iniciativas governamentais conduzidas pelo próprio MEC, como por exemplo, o Programa de Avaliação da Reforma Universitária - 
Paru, a constituição da "Comissão de Notáveis" e do Grupo Executivo da Reforma da Educação Superior - Geres (Polidori et al., 2006).

Após esta primeira fase de desenvolvimento das diversas formas de avaliação do ensino superior, com base em iniciativas de órgãos governamentais, no final da década de 1980, início de 1990, as IES desenvolveram formas de autoavaliação, que, conforme Polidori et al. (2006), se constituem em um processo de autoconhecimento da Instituição que busca organizar suas informações, construindo sentido sobre seus processos, estruturas e práticas voltadas a melhorar a qualidade de ensino mensurada em determinado período de tempo.

Assim, com este novo processo de avaliação feito pelas próprias Universidades, foi criado o Programa de Avaliação Institucional das Universidades Brasileiras (Paiub), apoiado pelo MEC. No entanto, à época ainda não havia uma forma de alinhamento de parâmetros para que a avaliação institucional seguisse os mesmos critérios em todo território nacional, o que necessitou criar uma nova ferramenta para avaliação do ensino superior brasileiro (Polidori et al., 2006).

Entre 1996 e 1997 foi criado o Exame Nacional de Cursos, popularmente conhecido como "Provão" (Polidori et al., 2006), que tinha como objetivo avaliar o desempenho organizacional das IES e regular o alto crescimento das instituições privadas no Brasil (Barreyro, 2008). Por meio dessa ferramenta, houve uma parametrização da qualidade, de forma a viabilizar a autorização e credenciamento dos cursos de graduação. Porém, somente o "Provão" não era capaz de organizar o sistema de ensino superior e por isso foram criadas mais duas ferramentas para auxiliar na avaliação de desempenho das IES, a Avaliação das Condições de Ensino e a Avaliação Institucional (Barreyro, 2008; Polidori et al., 2006).

Entretanto, após sete anos de vigência dessas ferramentas, o MEC ainda não conseguia estabelecer parâmetros de avaliação de desempenho de qualidade que atendessem as perspectivas de todas as IES no Brasil (Polidori et al., 2006). Por isso, em 2004, foi criado o Sistema Nacional de Avaliação da Educação Superior - Sinaes, que tem como objetivo ser um sistema integrado que permita o desenvolvimento de parâmetros de avaliação das políticas de ensino superior por parte de órgãos nacionais de educação, e do nível de qualidade e desempenho institucional inerente às IES (Brito, 2008; Polidori et al., 2006). Assim, o Sinaes, que é um sistema sob a responsabilidade do Instituto Nacional de Estudos e Pesquisas Educacionais Anísio Teixeira - Inep, assegura uma forma estruturada de avaliação das IES, atendendo às diretrizes da Comissão Nacional de Avaliação da Educação Superior - Conaes (Brito, 2008). O Sinaes está estruturado em três eixos para mensuração da qualidade do 
ensino superior brasileiro: a avaliação institucional das IES, dos cursos de graduação e dos discentes.

No âmbito do eixo da avaliação institucional e dos cursos de graduação, as IES, seguindo os critérios estabelecidos pela Lei $n^{\circ} 10.861 / 04$ e pela portaria $n^{\circ} 2.051$ de 9/7/2004 (MEC, 2004), criaram suas Comissões Próprias de Avaliação - CPA. O objetivo das CPA é identificar os pontos de melhoria necessários em termos de processos e infraestrutura, atendendo as expectativas de seu corpo docente, discente, colaboradores e comunidade externa, gerando resultados para seu Plano de Desenvolvimento Institucional (Brasil, 2004; Inep, 2004).

Já para a avaliação do desempenho dos discentes, que conforme Polidori et al. (2006) é o principal eixo para avaliação da qualidade do ensino superior devido a sua influência nos outros eixos do Sinaes, a ferramenta utilizada por todas as IES é o Exame Nacional de Desempenho de Estudantes (Enade). Por meio desse exame, as IES conseguem estabelecer indicadores que permitam uma análise profunda de seu discente, além de uma melhor compreensão para definir quais serão as ações estratégicas tomadas em relação aos potenciais alunos ingressantes na instituição e em seus cursos de graduação.

\subsection{O Exame Nacional de Desempenho de Estudantes - Enade}

O Enade foi criado há doze anos por uma iniciativa do Ministério da Educação - MEC, no âmbito do Sinaes, como uma forma de avaliação do corpo discente das IES e uma forma documental de apresentar os resultados de desempenho dos alunos nos diversos cursos ministrados nas instituições de ensino superior (Inep, 2016). Por ter este caráter avaliativo e comprobatório, é possível inferir que esse tipo de iniciativa é uma excelente oportunidade para as IES promoverem melhorias institucionais, reavaliar metodologias de ensino, readequar os conteúdos programáticos de cursos de graduação, avaliar o desempenho docente no caráter de transmissão do conhecimento e ser o fator preponderante para avaliação institucional obrigatória para comprovação da qualidade junto aos órgãos responsáveis.

Conforme Gomes et al. (2015), as estratégias nas IES ainda não foram profundamente estudadas, porém as pressões internas levam essas instituições a procurarem formas de atender e gerar demandas para seu público interno. Ainda conforme esses autores, as relações internas promovidas pelos discentes forçam as IES a procurar ferramentas que justifiquem as melhores práticas e apresentações dos serviços prestados. Por isso, o Enade apresenta-se como ferramenta estratégica (Teixeira, Maccari, \& Martins, 2016) que consegue suprir as 
diversas necessidades do corpo discente, como a relação do conteúdo teórico dos cursos com a prática no mercado de trabalho (Polidori et al, 2006), a validação das competências dos discentes no momento da conclusão do curso de graduação (Brito, 2008), o alinhamento do conhecimento geral do discente em relação a todos os outros alunos do mesmo curso no Brasil (Barreyro, 2008) e o reconhecimento da qualidade do curso para ingressantes (Schwartzman, 2008).

O Enade é composto por dois questionários que têm como objetivo entender o perfil do estudante egresso dos cursos presentes na grade da IES. O "Questionário do Estudante", definido pela Portaria $\mathrm{n}^{\mathrm{o}}$ 40, de 2007, republicada em 2010 (Inep, 2016), precisa ser respondido por todos os discentes que farão a avaliação. Caso o aluno não responda, sua situação fica como irregular no sistema do Inep, podendo prejudicar a conclusão das atividades obrigatórias em seu curso de graduação, assim como a situação da IES junto ao MEC. O segundo questionário é a "Avaliação Formal", que é promovida anualmente e, conforme o Art. 33-E da Portaria $n^{\circ}$ 40, de 2007, republicada em 2010 (Inep, 2016), define quais cursos de graduação serão avaliados no ano vigente. A partir dessa definição, a IES fica responsável pela mobilização e inscrição dos discentes que devem participar da avaliação, sendo de responsabilidade de seus coordenadores de curso e procuradores educacionais institucionais todas as ações para estas atividades. A prova do Enade é aplicada em locais definidos pelo Inep e informados às IES, assim como aos discentes elegíveis, daquele ano, e tem uma duração de quatro horas. A prova é dividida em questões discursivas e de múltipla escolha (objetivas), de formação geral e do componente específico da área e de percepção da prova, elencadas conforme Figura 1, totalizando 49 questões em seu total (Sinaes, 2014).

Figura 1: Divisão da prova do Enade por quesito e peso na avaliação conforme a especificidade das questões.

\begin{tabular}{|l|c|c|c|}
\hline \multicolumn{1}{|c|}{ Partes } & $\begin{array}{c}\text { Número das } \\
\text { questões }\end{array}$ & $\begin{array}{c}\text { Peso das } \\
\text { questões no } \\
\text { componente }\end{array}$ & $\begin{array}{c}\text { Peso dos } \\
\text { componentes no } \\
\text { cálculo da nota }\end{array}$ \\
\hline Formaçăo Geral/Discursivas & D1 e D2 & $40 \%$ & \multirow{2}{*}{$25 \%$} \\
\hline Formaçăo Geral/Objetivas & 1 a 8 & $60 \%$ & \multirow{2}{*}{$75 \%$} \\
\hline Componente Especifico/Discursivas & D3 a D5 & $15 \%$ & \multirow{2}{*}{$\cdot$} \\
\hline Componente Especifico/Objetivas & 9 a 35 & $85 \%$ & \\
\hline Questionário de Percepçăo da Prova & 1 a 9 & - & \multirow{2}{*}{} \\
\hline
\end{tabular}

Fonte: Sinaes, 2014 
Por ser um exame que avalia os conhecimentos dos discentes e auxilia nos critérios de qualidade das IES, todo o conteúdo da "Avaliação Formal" é alinhado com as Diretrizes Curriculares Nacionais, que são iguais para todas as IES do Brasil e, por isso, permitem a parametrização do aprendizado do discente do curso selecionado para avaliação por meio do Enade (Inep, 2016). Conforme Polidori et al. (2006), o alinhamento por meio das Diretrizes Curriculares Nacionais permite uma avaliação profunda sobre as competências obtidas pelos discentes no curso de graduação e sua relação com a formação acadêmica.

Os resultados obtidos por meio da "Avaliação Formal" e do "Questionário do Estudante" são as variáveis necessárias para o cálculo dos indicadores de qualidade da IES, que validam as notas dos cursos de graduação da instituição, tornando-se público a toda a comunidade e, principalmente, aos potenciais alunos que tenham interesse em ingressar em qualquer IES do Brasil (Inep, 2016). Por isso, o uso estratégico do Enade como ferramenta para avaliação do discente e, consequentemente, dos cursos e da instituição, é muito importante pelo fator da sustentabilidade financeira e institucional da IES (Galvão et al., 2011; Gomes et al., 2015). Além disso, com os indicadores obtidos por meio do Enade, vinculados à atuação da Comissão Própria de Avaliação - CPA (que é responsável pela avaliação interna baseada em 10 dimensões definidas pelo Sinaes), as IES conseguem prestar contas para os órgãos responsáveis pela avaliação da qualidade do ensino superior no Brasil (Barreyro, 2008; Brito, 2008; Inep, 2016; Polidori et al., 2006).

Ressalta-se, para um melhor entendimento, o conceito Enade, que é a nota do curso que se torna pública para toda a comunidade, é obtido por meio do desempenho discente dos concluintes nos critérios de Formação Geral - FG e Componente Específico - CE (Inep, 2014). Ainda, conforme o Inep (2014), as 30 questões referentes ao CE contribuem com $75 \%$ da nota, enquanto as 10 questões da FG complementam a nota com o peso de $25 \%$. Com tal composição, o curso pode ser avaliado com notas de 1 a 5 , entendendo que quanto maior a nota, melhor o desempenho no exame e, consequentemente, melhor a qualidade do curso.

De forma geral, o Enade traz às IES a possibilidade de entenderem melhor o perfil socioeconômico dos seus discentes, a evolução do conhecimento e competências destes discentes, promoverem melhorias nas metodologias didáticas dos cursos, avaliarem indiretamente o desempenho do docente, mensurar as melhores práticas de seu corpo administrativo no atendimento às necessidades do discente, além de ter a possibilidade de melhoria na nota dos cursos cedidos pelos órgãos governamentais responsáveis (Barreyro, 2008; Brito, 2008; Polidori et al., 2006; Schwartzman, 2008). 


\section{METODOLOGIA}

Para este artigo foi utilizado o método qualitativo de análise documental que, conforme Godoy (1995), é uma rica fonte de dados confiáveis e que permite ao pesquisador fazer uma análise profunda de determinado fenômeno. Para Bardin (2011), a análise documental possibilita que dados primários sejam analisados e interpretados para obtenção de resultados interessantes ao escopo da pesquisa. Além disso, por meio desta técnica de pesquisa qualitativa, é possível trabalhar com uma margem de tempo que permita uma análise com alto nível de precisão, o que evita alguns vieses dentro da pesquisa (Godoy, 1995).

Para obter dados que gerassem uma contribuição a outros pesquisadores e a outras IES, foi selecionado o curso de graduação em Administração, por se tratar de um dos principais cursos disponíveis na grade de opções ofertadas pela IES objeto deste artigo, além de ser uma área-chave para estudos futuros devido a sua cobertura acadêmica em diversas áreas do conhecimento como Estratégia.

A coleta dos dados foi feita diretamente do site do Inep (veja tela de acesso para Consulta aos Relatórios de Cursos, disponível na Figura 2), sendo extraídos os últimos três Relatórios de Resultados do Enade, ao qual o curso em Administração da IES foi selecionado para ser avaliado (Inep, 2006, 2009, 2012). Por meio da análise documental destes relatórios foram obtidos os dados necessários para apresentar a importância do Enade como ferramenta estratégica para a melhoria da qualidade do ensino do curso descrito, por meio do desempenho dos discentes.

Para que essa análise pudesse ser parametrizada e utilizada por outros pesquisadores foram utilizados cinco critérios para a análise do desempenho discente: 1) adesão do corpo discente; 2) média das notas das partes da prova; 3) percepção da prova pelo discente; 4) questionário do estudante; e 5) conceito Enade. 
Figura 2: Tela de acesso para Consulta aos Relatórios de Cursos.

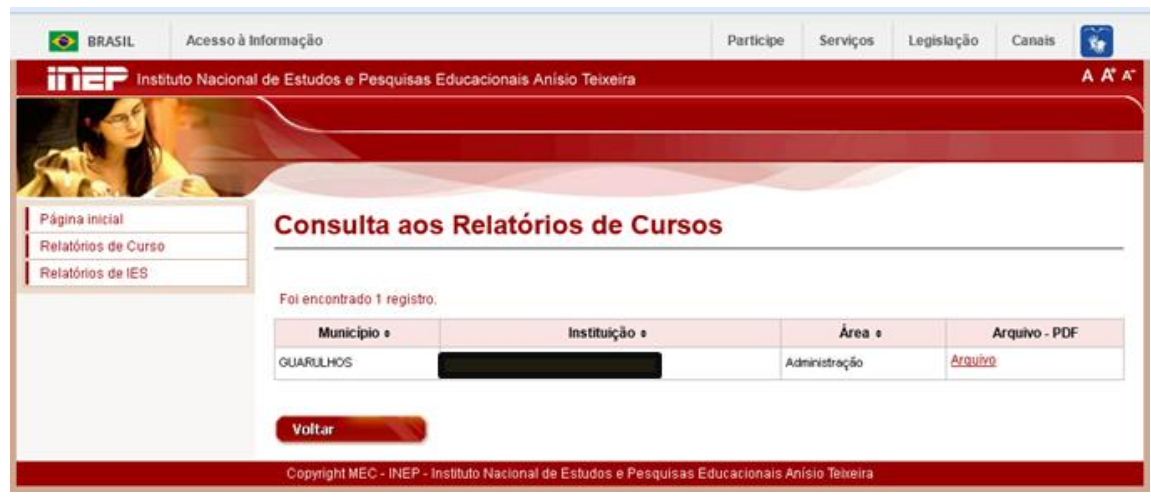

Fonte: http://enadeies.inep.gov.br/enadeIes/enadeResultado/

\section{APRESENTAÇÃO E DISCUSSÃO DOS RESULTADOS}

Com base nos Relatórios do Enade, e com acesso público pelo site do Inep, a IES, objeto deste estudo, pôde promover suas intervenções em cinco critérios estabelecidos, que permitiram verificar a adesão do corpo discente no dia do exame, a média das notas obtidas no Enade, a percepção da prova pelo discente, o perfil socioeconômico, e o processo de ensino-aprendizagem, além do conceito do Enade, que se trata da nota final do curso, mensurando sua qualidade, conforme já descrito em parágrafos anteriores.

A Figura 3A apresenta, de forma sucinta, a quantidade de discentes elegíveis para a prova do Enade nas últimas três avaliações em que o curso de Administração foi selecionado pelos critérios do Inep, além do número de presentes e sua relação percentual.

Nessa Figura 3A é possível notar que houve um trabalho considerável por parte da IES no sentido de mobilizar e sensibilizar seu corpo discente em relação à presença no dia da prova, entre os anos de 2006 e 2009, aumentando a relação percentual entre o total de discentes e presentes no dia do exame. Essa ação da IES se manteve até o ano de 2012 em que a relação percentual continuou em crescimento, comparada às duas avaliações anteriores do Enade.

Dessa forma, a atuação estratégica da IES, influenciada pela aplicação do Enade, incentivando a presença do discente no dia da "Avaliação Formal", poderá aumentar suas chances de obter melhores resultados, e por consequência, deverá melhorar a nota do curso, que é informada pelo órgão que regulamenta a qualidade dos cursos de graduação, o Inep. 
Figura 3A: Relação entre total de discentes elegíveis e alunos presentes nas últimas três provas do Enade do curso de Administração da IES, destacando-se a intervenção feita entre os anos de 2006 e 2012

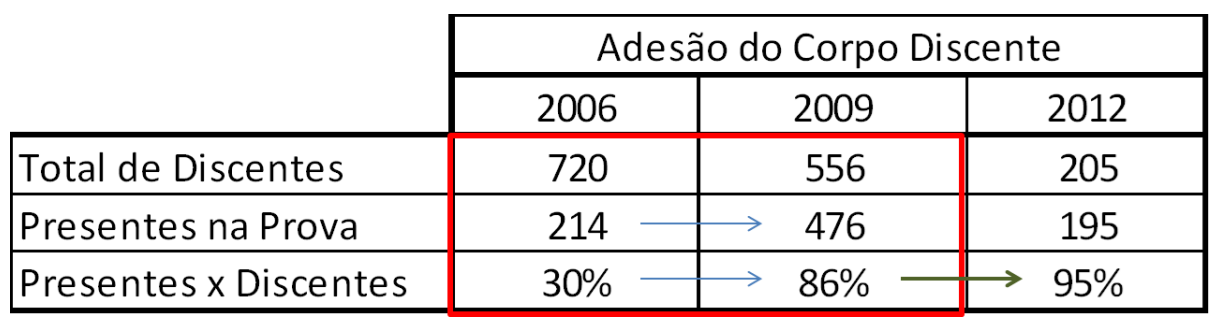

Fonte: Inep 2006, 2009, 2012. Adaptado pelo autor.

$\mathrm{Na}$ Figura 3B nota-se que, devido à aquisição de um grupo educacional com abrangência nacional no ano de 2007, o que gerou mudanças no corpo de gestão e acadêmico da IES, houve uma gradativa redução no número de alunos do curso de Administração (fato que se atribui às novas políticas estipuladas pelo grupo educacional). No entanto, o empenho do coordenador do curso e dos procuradores institucionais, foi essencial para que a relação de presentes na prova versus o total de discentes continuasse a crescer até o ano de 2012.

Este fato reduziu as justificativas da IES para o Inep sobre as abstenções, melhorando seus índices de avaliação interna institucional, o que gera uma vantagem competitiva dentro de um mercado concorrido, como o das IES (Gomes et al., 2015; Silva Ferreira, Boente, dos Santos, de Farias Brevilato, \& Boente, 2016).

Figura 3B: Apresentação da redução do número total de discentes do curso de Administração da IES e aumento da relação percentual de presentes no exame em relação ao total de discentes elegíveis.

\begin{tabular}{|l|c|c|c|}
\cline { 2 - 4 } \multicolumn{1}{c|}{} & \multicolumn{3}{c|}{ Adesão do Corpo Discente } \\
\cline { 2 - 4 } \multicolumn{1}{c|}{} & 2006 & 2009 & 2012 \\
\hline Total de Discentes & 720 & 556 & $\mathbf{2} 205$ \\
\hline Presentes na Prova & 214 & 476 & 195 \\
\hline Presentes x Discentes & $30 \%$ & $\uparrow 86 \%$ & $\uparrow 95 \%$ \\
\hline
\end{tabular}

Fonte: Inep 2006, 2009, 2012. Adaptado pelo autor.

Na Figura 4, em que é apresentada a Média das notas das partes da prova, verifica-se que a IES em 2006 obteve seu melhor desempenho nas últimas três avaliações do Enade, tendo uma queda representativa nos anos de 2009 e 2012, o que sugere, novamente, a conclusão do impacto na mudança do corpo diretivo e acadêmico da Instituição. 
Utilização do Enade (Exame Nacional de Desempenho de Estudantes) Como Ferramenta de Avaliação do Desempenho de Alunos de Uma Instituição de Ensino Supe rior Paulis tana

Além disso, infere-se que a IES não se utilizou de estratégias como a aplicação de simulados ou revisões dos conteúdos programáticos e/ou das metodologias para melhorar os resultados obtidos neste indicador, nos Enade 2009 e 2012. Conforme Barreyro (2008), tal indicador é um parâmetro básico para a mensuração da qualidade de ensino, feita pelo Inep.

Figura 4: Comparativo entre as médias das notas obtidas pelos discentes do curso de Administração da IES nas últimas três avaliações do Enade.

\begin{tabular}{|l|c|c|c|}
\cline { 2 - 4 } \multicolumn{1}{c|}{} & \multicolumn{3}{c|}{ Média das Notas } \\
\cline { 2 - 4 } \multicolumn{1}{c|}{} & 2006 & 2009 & 2012 \\
\hline Resultado Geral & 37 & 35,3 & $\Rightarrow$ \\
\hline Formação Geral & 37,5 & 42,4 & 43,3 \\
\hline Componente Específico & 36,9 & 33 & 30,4 \\
\hline
\end{tabular}

Fonte: Inep 2006, 2009, 2012. Adaptado pelo autor.

$\mathrm{Na}$ Figura 5A foi considerado o critério de Percepção da prova pelo discente, o que permitiu a IES entender as questões de dificuldade da prova do Enade, o entendimento dos enunciados das questões e das instruções iniciais da prova, além do tempo médio para que a prova fosse concluída, por parte de seu discente do curso de Administração.

É possível notar que o nível de dificuldade da prova do Enade nas últimas três avaliações obteve percepção igual em todos os anos. Entretanto, nota-se que nos anos de 2006 e 2009, os discentes consideraram que as instruções da prova eram pouco suficientes. Somente em 2012 tal percepção se tornou suficiente para execução do exame.

Figura 5A: Apresentação dos resultados do quesito "Instruções da Prova" pelos alunos da IES nas última três provas do Enade, com destaque para a mesma percepção destes discentes nos anos de 2006 e 2009.

\begin{tabular}{|l|c|c|c|}
\cline { 2 - 4 } \multicolumn{1}{c|}{} & \multicolumn{3}{c|}{ Percepção da Prova } \\
\cline { 2 - 4 } \multicolumn{1}{c|}{} & 2006 & 2009 & 2012 \\
\hline Dificuldade* & 3 & 3 & 3 \\
\hline Instruções da Prova** & 2 & 2 & 3 \\
\hline
\end{tabular}

Fonte: Inep 2006, 2009, 2012. Adaptado pelo autor.

* Conceito 3 = Nível Médio de Dificuldade

** Conceito 2 = Pouco Suficientes / Conceito $3=$ Suficientes 
Embora a percepção do aluno sobre as instruções da prova tenha melhorado entre 2006 e 2012, os resultados gerais nos exames, no decorrer destes anos, foi piorando gradativamente, conforme pode ser visto na Figura 5B. Assim, infere-se que houve um baixo comprometimento e interesse por parte dos discentes durante, principalmente, as últimas duas avaliações, que é uma das barreiras para avaliação do discente por meio do Enade (Schwartzman, 2008). Além disso, compreende-se que os conteúdos didáticos e metodologias utilizadas pela IES, no curso de Administração, podem ser revistos, estrategicamente, com objetivo de melhora nos resultados das próximas avaliações do Enade.

Figura 5B: Apresentação dos resultados do quesito "Instruções da Prova" pelos alunos da IES nas provas do Enade 2006, 2009 e 2012 em que nota-se uma melhora na percepção sobre as instruções da prova, mas que porém não se reflete no Resultado Geral obtido pelos discentes nas avaliações do Enade.

\begin{tabular}{|l|c|c|c|}
\cline { 2 - 4 } \multicolumn{1}{c|}{} & \multicolumn{3}{c|}{ Percepção da Prova } \\
\cline { 2 - 4 } \multicolumn{1}{c|}{} & 2006 & 2009 & 2012 \\
\hline Dificuldade* & 3 & 3 & 3 \\
\hline Instruções da Prova** & 2 & 2 & 3 \\
\hline Resultado Geral & 37 & 35,3 & 33,6 \\
\hline
\end{tabular}

Fonte: Inep 2006, 2009, 2012. Adaptado pelo autor.

* Conceito 3 = Nível Médio de Dificuldade

** Conceito 2 = Pouco Suficientes / Conceito $3=$ Suficientes

Na Figura 6, nota-se que houve uma mudança no perfil do estudante de Administração da IES, objeto deste artigo, que passou a ser oriundo, em sua grande maioria, de escolas particulares. Tal mudança pode ser entendida com base no novo posicionamento do grupo educacional que assumiu a gestão da IES, que acresceu os valores das mensalidades da Instituição. Com essa mudança, o impacto no número de alunos foi grande devido à evasão dos discentes, originários em sua maioria de escolas públicas, que não conseguiram mais subsidiar as mensalidades.

A ação do corpo diretivo da IES resultou na diminuição dos discentes do referido curso, gerando uma vantagem para os concorrentes, o que por sua vez pode originar um problema estratégico para a IES (Gomes et al., 2015; Silva Ferreira et al., 2016).

Figura 6: Mudança no perfil do aluno devido a mudança de posicionamento da IES, que teve uma queda no total de discentes elegíveis para as provas. 
Utilização do Enade (Exame Nacional de Desempenho de Estudantes) Como Ferramenta de Avaliação do Desempenho de Alunos de Uma Instituição de Ensino Supe rior Paulis tana

\begin{tabular}{|l|c|c|c|}
\cline { 2 - 4 } \multicolumn{1}{c|}{} & \multicolumn{3}{c|}{ Questionário do Estudante } \\
\cline { 2 - 4 } \multicolumn{1}{c|}{} & 2006 & 2009 & 2012 \\
\hline Faixa de Renda (salários mínimos) & 3 a 10 salários & 3 a 5 salários & 3 a 10 salários \\
\hline Horas Semanais de Trabalho & 20 a 40 horas & 20 horas & Sem informação \\
\hline Tipo de Escola (pública ou privada) & Pública & Pública & Pública/Privada \\
\hline Total de Discentes & 720 & 556 & 205 \\
\hline
\end{tabular}

Fonte: Inep 2006, 2009, 2012. Adaptado pelo autor.

Finalmente, na Figura 7, em que é tratado o critério Conceito Enade, nota-se que o impacto de todas as intervenções previamente apresentadas nesta seção por parte da IES ajudou, de alguma forma, na melhoria da nota do curso, com destaque para o esforço realizado sobre o critério Adesão do Corpo Discente. Para Polidori et al. (2006), os esforços sobre o corpo discente devem ser o principal fator que a IES considere em suas avaliações institucionais.

Pode-se inferir que, caso a IES prossiga com seu planejamento e ações estratégicas nas próximas avaliações do Enade, a nota poderá, ao menos, se manter em 3 ou subir para 4 ou 5 .

Figura 7: Últimas três notas obtidas pelo curso de Administração da IES, por meio do Conceito Enade.

\begin{tabular}{|c|c|c|}
\hline \multicolumn{3}{|c|}{ Conceito ENADE } \\
\hline 2006 & 2009 & 2012 \\
\hline 2 & 2 & 3 \\
\hline
\end{tabular}

Fonte: Inep 2006, 2009, 2012. Adaptado pelo autor.

\section{CONSIDERAÇÕES FINAIS}

O presente artigo justificou a aplicação do Enade como ferramenta estratégica para avaliação do desempenho discente no curso de Administração de uma IES, possibilitando entender o perfil dos alunos e aprimorar a qualidade de seus serviços de ensino, além de ser uma forma de contribuir para a avaliação interna institucional, permitindo a prestação de contas aos órgãos responsáveis pela avaliação da qualidade do ensino superior no Brasil.

Os resultados apresentados demonstram a eficácia no uso desta ferramenta, o Enade, de forma estratégica para que a IES possa, rapidamente, promover melhorias que impactem, positivamente, na qualidade de ensino aos discentes (Polidori et al., 2006) e um incremento 
nas avaliações institucionais (Brito, 2008; Schwartzman, 2008), além evidentemente de manter a sua sustentabilidade econômica (Galvão et al., 2011).

Um ponto importante a ser ressaltado é que a análise foi feita em sua totalidade com base em documentos que estão disponíveis no site do Inep, de domínio público e acesso livre a toda a comunidade, o que permite verificar a atuação da IES para promover melhorias, visando entregar um serviço de ensino de qualidade aos ingressantes dos cursos de graduação. Ademais, tais documentos podem ser utilizados pela IES como relatórios gerenciais para apresentação de resultados prévios e planejamento de ações futuras na organização.

As principais limitações deste artigo se resumem à restrição da análise somente aos documentos obtidos no site do Inep e aos resultados que estes fornecem. Toda a interpretação dos dados necessita ser conduzida sobre esses documentos, e sempre de forma comparativa aos relatórios anteriores. Além disso, com a evolução dos métodos aplicados no Enade, os critérios podem sofrer mudanças, o que talvez não permita comparações futuras e válidas para alguns estudos relacionando às estratégias de avaliação do ensino superior.

Por fim, ressalta-se a importância de estudos futuros que envolvam o Enade para avaliação do desempenho discente aliados às pesquisas que utilizem ferramentas computacionais para avaliação do desempenho docente, como o Scriptsucupira (R. R. N. Ferraz, Silva, Ramão, di Petta \& Alves, 2016), e Scriptlattes (Ferraz, Quoniam \& Maccari, 2015) de forma que se tenha uma visão da avaliação institucional mais completa e profunda, auxiliando as IES na prestação de contas aos órgãos de avaliação da qualidade do ensino superior no Brasil.

\section{REFERÊNCIAS}

Bardin, L. (2011). Análise de conteúdo (Edições 70). Lisboa. Recuperado em 2 julho, 2016, de http:/docslide.com.br/documents/bardin-laurence-analise-de-conteudopdf.html

Barreyro, G. B. (2008). De exames, rankings e mídia. Avaliação: Revista da Avaliação da Educação Superior (Campinas), 13(3), 863-868. https $/ /$ doi.org/10.1590/S141440772008000300017 
Borges, A. P. A. de A., Cabral, E. V. \& Petri, S. M. (2014). Proposta de BSC para instituição de ensino superior privada sob a perspectiva de clientes. Reavi - Revista Eletrônica do Alto Vale do Itajaí, 3(3), 49-61.

Brasil (2004). Diretrizes para a Avaliação das Instituições de Educação Superior. Recuperado em 25 maio, 2016, de http://portal.mec.gov.br/

Brito, M. R. F. de (2008). Sinaes e Enade: Da concepção à implementação. Avaliação: Revista da Avaliação da Educação Superior (Campinas), 13(3), 841-850. https://doi.org/10.1590/S1414-40772008000300014

Corrêa, H. L. \& Hourneaux Jr., F. (2008). Sistemas de mensuração e avaliação de desempenho organizacional: estudo de casos no setor químico no Brasil. Revista Contabilidade \& Finanças, 19(48), 50-64.

Ferraz, R. R. N., Quoniam, L. M. \& Maccari, E. A. (2015). A utilização da ferramenta Scriptlattes para extração e disponibilização on-line da produção acadêmica de um programa de pós-graduação stricto sensu em Administração. Revista Brasileira de Pós-graduação, 11(24). Recuperado em 16 setembro, 2016, de http://ojs.rbpg.capes.gov.br/index.php/rbpg/article/view/445

Ferraz, R. R. N., Silva, M. V. C. da, Ramão, G. B. \& Petta, A. di. (2016). Uso da ferramenta computacional Scriptsucupira para gestão estratégica da produtividade em pesquisa de um programa de Pós-graduação stricto sensu em biofotônica. Revista de Administração da Unimep, 14(3), 232-252.

Ferraz, R. R. N., Silva, M. V. C., Ramão, G. B., di Petta, A. \& Alves, W. A. L. (2016). Uso da ferramenta computacional scriptsucupira para gestão estratégica da produtividade em pesquisa de um programa de pós-graduação stricto sensu em biofotônica. Revista de Administração da Unimep, 14(3), 231-251. https://doi.org/10.15600/16795350/rau.v14n3p231-251

Galvão, H. M., Corrêa, H. L. \& Alves, J. L. (2011). Modelo de avaliação de desempenho global para instituição de ensino superior. Recuperado em 9 julho, 2016, de http:/www.redalyc.org/articulo.oa?id=273421614008 
Godoy, A. S. (1995). Pesquisa qualitativa - tipos fundamentais. Revista de Administração de Empresas, 35(3), 20-29.

Gomes, V., Machado-Taylor, M. de L., Saraiva, E. V. \& Santos, C. M. (2015). A Estratégia como prática nas Instituições de Ensino Superior. Revista Evidência, 11(11), 115-126.

Inep (2004). Orientações Gerais para o roteiro da Autoavaliação das Instituições, 1-38.

. (2006). Enade 2006 - Resultado de Curso - Administração. Recuperado em 22 agosto, 2016, de http://enadeies.inep.gov.br/enadeIes/enadeResultado/

. (2009). Enade 2009 - Resultado de Curso - Administração. Recuperado em 22 agosto, 2016, de http://enadeies.inep.gov.br/enadeIes/enadeResultado/

. (2012). Enade 2012 - Resultado de Curso - Administração. Recuperado em 22 agosto, 2016, de http://enadeies.inep.gov.br/enadeIes/enadeResultado/

. (2014). Enade 2014 - Resultado de Curso - Licenciatura em Pedagogia. Recuperado em 03 julho, 2016, de http//enadeies.inep.gov.br/enadeIes/enadeResultado/

(2016). Manual Enade 2016. Recuperado em 02 julho, 2016, de http://download.inep.gov.br/educacao_superior/enade/manuais/manual_do_enade_010 72016.pdf

Kennerley, M. \& Neely, A. (2003). Measuring Performance in changing business enviroment. International Journal of Operations \& Production Management, 23(2), 213-229. https://doi.org/http://dx.doi.org/10.1108/01443570210450293

Lotta, G. S. (2002). Avaliação de desempenho na área pública: perspectivas e propostas frente a dois casos práticos. RAE-eletrônica, 1(2), 1-12.

Martins, R. A. \& Neto, P. L. C. (1998). Indicadores de desempenho para a gestão pela qualidade total: uma proposta de sistematização. Gestão \& Produção, 5(3), 298-311.

MEC (2004). Regulamentação dos procedimentos de avaliação do Sistema Nacional de Avaliação da Educação Superior (Sinaes). Recuperado em 16 junho, 2016, de http://portal.mec.gov.br/arquivos/pdf/PORTARIA_2051.pdf 
Polidori, M. M., Marinho-Araujo, C. M. \& Barreyro, G. B. (2006). Sinaes: perspectivas e desafios na avaliação da educação superior brasileira. Ensaio, 14(53), 425-436.

Schwartzman, S. (2008). O "conceito preliminar" e as boas práticas de avaliação do ensino superior. Estudos: Revista da Associação Brasileira de Mantenedoras de Ensino Superior, 26(38), 1-22.

Silva Ferreira, V. M., Boente, P. A. N. P., dos Santos, R. M., de Farias Brevilato, F. V. \& Boente, K. P. (2016). A Autoavaliação institucional no ensino superior como técnica de gestão estratégica. Revista Edu. Tec., 1(1). Recuperado em 02 julho, 2016, de http://revista.faeterj-caxias.net/index.php/edutec/article/download/281/286

Sinaes (2014). Enade 2014 - Pedagogia. Recuperado em 03 julho, 2016, de http://download.inep.gov.br/educacao_superior/enade/provas/2014/36_pedagogia.pdf

Teixeira, G. C. dos S., Maccari, E. A. \& Martins, C. B. (2016). Influence of regulation of Capes (Coordenação de Aperfeiçoamento de Pessoal de Nivel Superior) in strategic management of educational projects. Revista Gestão \& Tecnologia, 16(2), 238-259. 